\title{
Why smoke fewer cigarettes?
}

\author{
D O HO-YEN, V A SPENCE, J P MOODY, W F WALKER
}

\begin{abstract}
Sixteen volunteers were tested when smoking their own brand of cigarettes normally and when smoking half their usual number of cigarettes. While smoking half their usual amount the subjects changed their inhalation behaviour. Over this period the percentages of carboxyhaemoglobin were not significantly different from steady-state values whereas plasma nicotine concentrations rose significantly. With the reduction in cigarettes there were significant falls in haemoglobin concentration, packed cell volume, and red cell count.

These findings suggest that the advice given to patients to smoke fewer cigarettes should be accompanied by a warning against increasing inhalation. Patients who say that they have reduced their smoking but who have unaltered carboxyhaemoglobin concentrations should not be discredited.
\end{abstract}

\section{Introduction}

Smokers are being encouraged to stop smoking, but only one in four succeeds in stopping permanently before the age of $60 .{ }^{1}$ For most smokers the harmful effects of cigarettes can be minimised only by changing to a "safer" cigarette or reducing the number of cigarettes smoked. The benefits of these choices, however, are not easy to identify as the relative toxicities of tar, nicotine, carbon monoxide, and other smoke-related factors are not clearly defined.

Medium-nicotine cigarettes with a low tar : nicotine ratio have been advocated as safer, ${ }^{2}{ }^{3}$ yet when this hypothesis was tested ${ }^{4}$ it was found that these cigarettes were "oversmoked" and thus

Ninewells Hospital and Medical School, Dundee DD1 9SY

D O HO-YEN, BMSC, MB, senior registrar, haematology section, department of pathology

V A SPENCE, PHD, senior physicist, vascular laboratory and department of medical physics

J P MOODY, PHD, senior biochemist, department of biochemical medicine W F WALKER, DSC, FRCS, consultant surgeon, department of surgery any benefit was questionable. Smokers appear to have a great tendency to change their smoking behaviour with different cigarettes. ${ }^{45}$ We suggested that this may also happen when patients are told to smoke fewer cigarettes. ${ }^{6}$

Smoking fewer cigarettes may have several advantages. If carboxyhaemoglobin concentrations are lower there may be a reduced risk of developing symptoms of atheroma ${ }^{7}$ and fewer failures in patients requiring reconstructive vascular surgery. ${ }^{8}$ Patients with intermittent claudication also show increased survival, ${ }^{9}$ though the reason for this is unclear. Almost all patients who maintain that they have reduced their smoking, however, are not believed. ${ }^{10}{ }^{11} \mathrm{We}$ designed this study to measure changes in plasma nicotine and carboxyhaemoglobin concentrations and common haematological variables in volunteers who reduced their cigarette consumption by half.

\section{Subjects and methods}

Twenty-one healthy volunteers who were strongly motivated to stop smoking took part. Five did not complete the study: two were unable to reduce the number of cigarettes smoked; one had a virus infection; one was anaemic; and one inadvertently smoked hand-rolled cigarettes instead of his usual brand. Thus 16 (seven men, nine women) with an average age of 38 years took part. All were inhaling smokers of kingsize, filter-tipped cigarettes (mean $( \pm S D)$ tar yield $18 \pm 1 \mathrm{mg} /$ cigarette and mean nicotine yield $1 \cdot 3+0 \cdot 2 \mathrm{mg} /$ cigarette).

Subjects were seen in the late afternoon on three occasions in two weeks. Throughout they smoked their own brand of cigarettes. Initially, they answered a questionnaire on their smoking habits and a blood sample was taken. For a control week they smoked normally, recording hourly on a time chart provided by us the number of cigarettes smoked. At the end of the control week their cigarette consumption was calculated from the chart and targets set so that for the last week their consumption was reduced by half, after which a second blood sample was obtained. The initial questionnaire was answered again. The questionnaire assessed the amount of smoke inhaled on a five-point scale, the duration of inhalation on a three-point scale, and the length of cigarette smoked. Blood samples were taken two minutes after the subject had smoked a cigarette. Each sample was processed through a Coulter $S$ and a reticulocyte count done. Plasma nicotine concentration was assayed using a gas-liquid chromatographic method based on that of Feyerabend and Russell. ${ }^{12}$ Carboxyhaemoglobin concentration was determined by using an IL182 co-oximeter (Instrumentation Lab Inc). 


\section{Results}

Before the control week subjects stated that their mean daily cigarette consumption was $29 \pm 9$ (range 20-45); during the control week their mean consumption was found to be $30 \perp 8$ (range 20-45), and this was reduced by half during the last week to $15+4$ (range 1022).

The table shows the mean values of variables in the blood at the two sampling times. Smoking fewer cigarettes resulted in an increase in plasma nicotine concentration $(\mathrm{p}<0.01)$, but carboxyhaemoglobin concentrations remained the same. There were no significant dif-

Values of variables measured in blood samples obtained before and after subjects reduced their smoking by half

\begin{tabular}{|c|c|c|c|c|}
\hline & \multicolumn{2}{|c|}{ Mean $\pm S D$ values } & \multirow{2}{*}{ Mean difference $\pm S E$} & \multirow[b]{2}{*}{$t$ test } \\
\hline & $\begin{array}{l}\text { Before } \\
\text { reduction }\end{array}$ & $\begin{array}{c}\text { After } \\
\text { reduction }\end{array}$ & & \\
\hline Plasma nicotine ( $\mathrm{nmol} / \mathrm{l})$ & $\begin{array}{l}106 \cdot 0 \\
(\div 43 \cdot 3)\end{array}$ & $\begin{array}{c}154 \cdot 8 \\
(+61 \cdot 0)\end{array}$ & $48.81: 14.02$ & $p \cdot 0 \cdot 01$ \\
\hline Carboxyhaemoglobin $\left({ }_{0}^{0}\right)$ & $\begin{array}{c}7 \cdot 7 \\
(+2 \cdot 3)\end{array}$ & $\begin{array}{c}7.9 \\
(+2 \cdot 3)\end{array}$ & $0.19 \pm 0.35$ & NS \\
\hline Haemoglobin $(\mathrm{g} / \mathrm{dl})$ & $\begin{array}{c}14 \cdot 57 \\
(+1.26)\end{array}$ & $\begin{array}{c}13.96 \\
(+1.17)\end{array}$ & $0.61+0.11$ & $\mathrm{p}: 0.001$ \\
\hline Packed cell volume & $\begin{array}{c}0.428 \\
+0.032)\end{array}$ & $\begin{array}{c}0.412 \\
(+0.029)\end{array}$ & $0.017 \pm 0.004$ & $p \cdot 0.01$ \\
\hline Red cell count $\left(\times 10^{9} / 1\right)$ & $\begin{array}{c}4820 \\
(+380)\end{array}$ & $\begin{array}{c}4620 \\
(. t 380)\end{array}$ & $200+50$ & $\mathrm{p} \cdot 0.001$ \\
\hline
\end{tabular}

Conversion: SI to traditional units-Nicotine: $1 \mathrm{nmol} / 1 \approx 16.2 \mathrm{ng} / 100 \mathrm{ml}$.

ferences between the samples in white cell count, mean corpuscular volume, mean corpuscular haemoglobin concentration, mean corpuscular haemoglobin, and reticulocyte count. There was however, a significant fall in haemoglobin concentration $(p<0.001)$, packed cell volume $(p<0.01)$, and red cell count $(p<0.001)$.

The figure shows the results of the questionnaire and of the signtest analysis. When the number of cigarettes smoked was halved there was a significant increase in the duration of inhalation $(p<0.02)$ and amount of cigarette smoked $(p<0.01)$ and overall exposure to smoke from each cigarette was greater $(p<0.002)$.

\section{Discussion}

Patients who claim to have reduced their smoking are not believed. ${ }^{1011}$ Their truthfulness is usually tested by measuring serum thiocyanate or carboxyhaemoglobin concentrations. ${ }^{8-10}$ When our subjects smoked fewer cigarettes their carboxyhaemoglobin concentrations were not significantly different from steady-state values; thus it could be argued that they were being dishonest. Two important factors, however, should be considered. Firstly, our subjects were highly motivated volunteers. There was always the option for them to leave the study, and indeed two subjects withdrew rather than reduce their smoking. Secondly, the haematological results were consistent with them having reduced their cigarette consumption. Increases in haemoglobin concentration, packed cell volume, and red cell count with smoking are well documented, ${ }^{14-16}$ as is also a reduction in these values when smoking ceases. ${ }^{14}$. Thus smokers reducing their cigarette consumption modify their smoking behaviour, which may result in unchanged carboxyhaemoglobin concentrations. The alternative-that most of our volunteers who maintained that they had reduced their smoking were being dishonest-seems unlikely. Consequently carboxyhaemoglobin concentrations, while useful in detecting smokers from non-smokers, may have limited application in patients who reduce their smoking.

When smoking half their usual number of cigarettes subjects reported a change in smoking behaviour $(\mathrm{p}<0.002)$. This resulted in exposure to more smoke from each cigarette. Thus plasma nicotine concentration in the second blood sample was increased, which reflects the intensity with which the presample cigarette was smoked. Smokers are extremely versatile and can change their smoking behaviour to maintain nicotine concentrations with various types of cigarettes. ${ }^{517}$ Therefore, smoking fewer cigarettes or low-nicotine cigarettes may not? reduce the smoker's exposure to nicotine.

Carboxyhaemoglobin, because of its long half life, is onlyc slightly influenced by the pre-sample cigarette. Thus, carboxy- $\widehat{\widehat{\Omega}}$ haemoglobin concentration assessed late in the day is a good $\bar{F}$ reflection of the subject's steady-state concentration. Surpri-ग singly, our subjects maintained a high carboxyhaemoglobin con- $\infty$ centration while smoking half their usual number of cigarettes. At these concentrations there is an increased risk of symptoms. from atheroma, " decreased duration of exercise until the onset of $\overrightarrow{\vec{m}}$ angina, ${ }^{18}$ reduced exercise tolerance in chronic bronchitis and emphysema, ${ }^{19}$ and increased failure rate in reconstructive vascu-

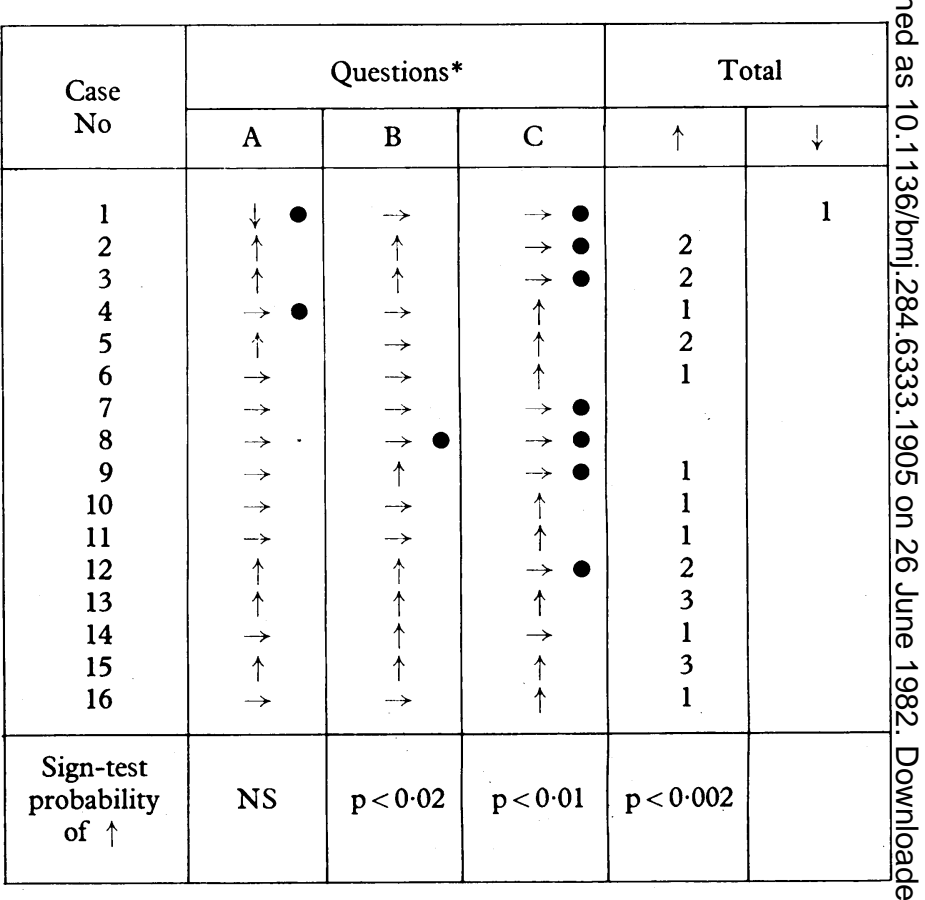

Results of questionnaire on changes in smoking behaviour during study. Arrows indicate increased $(\uparrow)$, reduced $(\downarrow)$, or same $(\rightarrow)$ amount of inhaled $\overline{\bar{A}}$ smoke, duration of inhalation, or amount of cigarette smoked. indicates that patient started at maximum of scale used.

*Question A: Amount of smoke inhaled. Question B: Duration of inhalation. Question C: Length of cigarette smoked.

lar surgery. ${ }^{8}$ Thus smoking fewer cigarettes may not reduceo many of the harmful effects of carboxyhaemoglobin.

There have been few studies on the advantages of smokingô fewer cigarettes. In part this has been due to the difficulty in $३$ objectively confirming the reduction in smoking. Hughson et $^{\circ}{ }^{\circ} \mathrm{O}$ showed an increase in survival in patients who stop or reducen smoking. As those smoking less were combined with those who stopped smoking, however, it is difficult to be certain of theo individual advantage of smoking fewer cigarettes. Another study. showed that smoking increased the red cell mass, which could noto be due to hypoxaemia since the subjects were healthy youngw volunteers with normal blood gas concentrations. ${ }^{15} \mathrm{~A}$ possible explanation of the raised red cell mass in smokers is that smokingo may have a direct action on erythropoietin production. If this isळ so a reduction in smoking might result in a fall in haemoglobin? concentration, packed cell volume, and red cell mass. This seems to be unrelated to changes in nicotine or carboxyhaemo $\frac{O}{\mathbb{D}}$ globin concentrations. Possibly smoking fewer cigarettes may be? beneficial to patients by lowering blood viscosity as a result of å reduced red cell mass. Nevertheless, the harmful effects of nicotine and carboxyhaemoglobin may still be present. Thus patientso should be cautioned that a change in inhalation behaviour mayo negate some beneficial effects of smoking fewer cigarettes.

We are grateful to Dr A S Todd for reviewing the manuscript; Dr W Fee for helpful advice, and Miss E Flett for secretarial help. 


\section{References}

${ }^{1}$ Lee PN. Statistics of smoking in the United Kingdom. (Research paper 1.) 7th ed. London: Tobacco Research Council, 1976

${ }^{2}$ Russell MAH. Low-tar medium-nicotine cigarettes: a new approach to safer smoking. $\mathrm{Br}$ Med $\mathcal{F} 1976 ; \mathrm{i}: 1430-3$.

${ }^{3}$ Jarvis $M$. Less hazardous smoking. In: Greenhalgh RM, ed. Smoking and arterial disease. Bath: Pitman Press, $1981: 293-8$.

- Stepney R. Would a medium-nicotine, low-tar cigarette be less hazardous to health ? Br Med f $1981 ; 283: 1292-6$.

5 Ashton H, Stepney R, Thompson JW. Self-titration by cigarette smokers. Br Med f 1979;ii:357-60.

- Spence VA, Ho-Yen DO. Puff volume increases when low-nicotine cigarettes are smoked. $\mathrm{Br} \mathrm{Med} \mathcal{F} 1981 ; 283: 730-1$.

7 Wald N, Howard S, Smith PG, et al. Association between atherosclerotic disease and carboxyhaemoglobin levels in tobacco smokers. $\mathrm{Br} \mathrm{Med} \mathcal{f}$ $1973 ; \mathrm{i}: 761-5$

${ }^{8}$ Greenhalgh RM. Biochemical abnormalities and smoking in arterial ischaemia. In: Bergan JJ, Yao JST, ed. Gangrene and severe ischaemia of the lower extremities. New York: Grune and Stratton, 1978

${ }^{9}$ Hughson WG, Mann JI, Tibbs DJ, Woods HF, Walton I. Intermittent claudication: factors determining outcome. $\mathrm{Br}$ Med $\mathcal{F}$ 1978;i:1377-9.

${ }^{10}$ Kirk CJC, Lund VJ, Woodcock NE, Greenhalgh RM. The effect of advice to stop smoking on arterial disease patients, assessed by serum thiocyanate levels. 7 Cardiovasc Surg (Torino) $1980 ; 21: 568-9$.

${ }^{11}$ Kirk CJC, Woodcock NE, Lund VJ. The effect of advice to stop smoking on arterial patients assessed by serum thiocyanate levels. In: Greenhalgh RM, ed. Smoking and arterial disease. Bath: Pitman Presc, 1981:118-21.

12 Feyerabend C, Russell MAH. Improved gas-chromatographic method and micro-extraction technique for the measurement of nicotine in biological fluids. F Pharm Pharmacol 1979;31:73-6.

13 Turner JAMcM, Bell KP, Sillett RW. Deception among cigarette smokers. In: Greenhalgh RM, ed. Smoking and arterial disease. Bath: Pitman Press, $1981: 60-3$.

14 Eisen ME, Hammond EC. The effect of smoking on packed cell volume, red cell counts, haemoglobin and platelet counts. Can Med Assoc $\mathcal{F}$ $1956 ; 75: 520-3$.

15 Sagone AL, Lawrence T, Balcerzak SP. Effect of smoking on tissue oxygen supply. Blood $1973 ; 41: 845-51$.

${ }^{16}$ Isager H, Hagerup L. Relationship betweeen cigarette smoking and high packed cell volume and haemoglobin levels. Scand $\mathcal{F}$ Haematol 1971 8:241-4.

${ }^{17}$ Russell MAH, Jarvis M, Iyer R, Feyerabend C. Relation of nicotine yield of cigarettes to blood nicotine concentrations in smokers. $\mathrm{Br} \mathrm{Med} \mathcal{J}$ $1980 ; 281: 972-6$.

${ }^{18}$ Aronow WS. Effect of non-nicotine cigarettes and carbon monoxide on angina. Circulation 1980;61:262-5.

19 Calverley PMA, Leggett RJE, Flenley DC. Carbon monoxide and exercise tolerance in chronic bronchitis and emphysema. $\mathrm{Br} M e d \mathcal{F} 1981 ; 283$ 878-80.

(Accepted 30 April 1982)

\title{
Synergy between thinness and intensive sports activity in delaying menarche
}

\author{
JAN P VANDENBROUCKE, A VAN LAAR, H A VALKENBURG
}

\begin{abstract}
In a study to assess the effects of intensive physical activity and thinness on menarche records of 648 girls aged 10-14 were analysed. The girls were classified as thin or not thin on the basis of their body mass index, and whether or not they engaged in intensive sports activity was established. The presence of either thinness or intensive sports activity was associated with roughly a twofold decrease in the proportion of girls who had reached menarche; the presence of both factors was associated with roughly a fourfold decrease. These results did not appear to depend on age.
\end{abstract}

Thus intensive sports activity and thinness appear to have a synergistic effect in delaying menarche.

\section{Introduction}

Two recent reports by Frisch et al ${ }^{2}$ showed an association between intensive physical activity, thinness, and delayed menarche. It is difficult, however, to disentangle the potential effects of thinness and physical activity: the first report described the experience of ballet dancers, in whom both factors occur together, 1 and the second dealt predominantly with college athletes, augmented by only a small control group. ${ }^{2}$ To gain insight into the respective roles of both factors a comparison should be made between equally thin girls who do and do not

\footnotetext{
Institute of Epidemiology, Faculty of Medicine, Erasmus University Rotterdam, PO Box 1738, 3000 DR Rotterdam, The Netherlands JAN P VANDENBROUCKE, MD, MSC, research epidemiologist $A$ vAN LAAR, systems analyst H A VAL K̈ENRIIRG, MD, PHD, professor of epidemiology
}

engage in intensive physical activities, and vice versa. We found such a comparison could be made by reanalysing data previously collected during a population survey. Elsewhere ${ }^{3}$ we showed that the data from this survey are compatible with the hypothesis of an association between thinness and delayed menarche. Here, we have added physical activity to the analysis and looked into the interaction of both factors.

\section{Subjects, methods, and results}

Between 1975 and 1978 a population survey was undertaken in the Dutch town of Zoetermeer, a suburb near the Hague, to determine the prevalence of several chronic diseases and their determinants. Of a total of 13462 invited inhabitants aged 5 and over, 10532 participated. The overall response rate was $78 \%$; in children and adolescents the response rate was $82 \%$ or higher. All participants were measured and weighed in indoor clothing and without shoes. Female subjects, in a part of the survey directed at establishing the prevalence of infections of the lower urinary tract, were asked about their age at menarche. In another part of the survey, directed at cardiovascular risk factors, we collected information about sports activity. In particular, we determined whether a person was engaged in intensive sports activity as a member of a sports club or participated in competition sport, or both.

The records of 648 girls aged 10-14 at the time of sampling were analysed. We classified the girls as being thin or not thin on the basis of the body mass index (weight in $\mathrm{kg} /\left(\right.$ height in $\mathrm{m}$ ) ${ }^{2}$ ), which is regarded as the best weight:height index for obesity. ${ }^{4}$ Thinness was defined as a body mass index of 17 or smaller. Likewise, we constructed yes-or-no categories for intensive sports activity, based on the information about membership of a sports club or participation in competition sport. In all four combinations of these categories we counted the number of girls who had reached menarche at the time of the survey.

The table shows the results. The presence of either thinness or intensive sports activity was associated with roughly a twofold decrease in the proportion of girls who had reached menarche. When both factors were present the decrease was about fourfold. 